\title{
Study of the Optical Characteristics of Aluminim Doped Zno Thin Film
}

\section{Samuel IN and Emmanuel IU*}

Department of Industrial Physics, Faculty of Science, Ebonyi State University, Abakaliki, Nigeria

*Corresponding author: Emmanuel IU, Department of Industrial Physics, Faculty of Science, Ebonyi State University, Abakaliki, Nigeria, Email: ugwuei@yahoo.com

\section{Investigation Paper}

Volume 5 Issue 1

Received Date: March 19, 2020

Published Date: April 03, 2020

DOI: $10.23880 /$ nnoa-16000181

\section{Abstract}

In this work, the study on the influence of the aluminium on the optical properties of ZnO thin film was carried out with a focus on the influence of variation of aluminium ions on the optical behaviour of the ZnO thin film. The film was deposited on the glass substrates by chemical bath deposition technique and aluminium was used in the following varied quantity 0.1 , 0.2 , and $0.3 \mathrm{M}$ to dope the thin films respectively. The solutions were prepared using zinc sulphate, ammonia and Hexamine with aluminium nitrate. The optical characteristics of the film such as the spectral absorbance, reflectance and transmittance within the ultraviolet and near infra-red region of electromagnetic wave spectra were investigated using UV-VIS spectroscopy with the energy band gap found to be in the range of $3.5 \mathrm{eV}$ to $3.9 \mathrm{eV}$.

Keywords: Zinc Oxide; Aluminium; Influence; doping; chemical bath deposition; Optical properties; Band gap

\section{Introduction}

Lately, ZnO thin films has become major focus among all the oxide based thin films and as a result has attracted attention of nanoscientists with a lot of ongoing work on ZnO thin film including review and analysis of functionalities and applications of the film in both microelectronics and Photovoltaic cells [1] and as a filter to electromagnetic radiations coupled with the fact that its properties could easily be improved upon by doping and annealing which also results in tailoring the film to another area of application such as Sensors. This thin film material is a II-VI compound semiconductor with a hexagonal wurtzite crystal lattice structure. $\mathrm{ZnO}$ is also seen as a better replacement for Indium tin oxide widely used as transparent conducting oxides TCO [2] because it is more abundant and non toxic. Zinc Oxide thin film is found to have a large band gap of about $3.33-3.37 \mathrm{eV}$, It is one of the potential materials for being used as a TCO due to its good optical and electrical properties Zinc Oxide (ZnO) thin films is an inexpensive n-type semiconductor having large and direct band gap of about $3.3 \mathrm{eV}$ and is one of the most potential materials for used as a TCO because of its good electrical and optical properties, abundance in nature, $[3,4]$ and the ability to deposit these films at relatively low substrate temperatures [5]. Pure ZnO thin films are not stable against corrosive environment as adsorption of dioxygen in the films decreases the electrical conductivity and also modifies the surface morphology [6]. These films become more stable by doping them with trivalent metal cations [7-10] especially with aluminium [11]. Al doped $\mathrm{ZnO}$ is cheap, more abundant, non-toxic and has good stability in hydrogen plasma and above all its optical and electrical property can be improved or modified by controlling their doping concentrations [12], which is critical to achieving optimal functionalities and applicabilities of TCO-based devices. Therefore, it is useful to investigate the correlation between the optical properties of Al-doped $\mathrm{ZnO}$ films and the concentration of $\mathrm{Al}$ doping.

Numerous techniques have already been used to deposit both doped and undoped $\mathrm{ZnO}$ thin films on different substrate including spray pyrolysis [6], organ metallic chemical vapour deposition [13], pulsed laser deposition [14], sputtering 
[15], and sol-gel process [4]. Among these, Chemical bath deposition, (CBD) is relatively new and a less investigated process credited with several advantages, such as deposition of high purity, homogeneous, cheaper, large-area films at relatively low temperatures. Having discovered from the ongoing study that pure $\mathrm{ZnO}$ thin films are not stable against the corrosive environment because of adsorption of dioxygen in the film, the film is found to be more stable by doping them especially with aluminium which has been achieved using spry pyrolitic technique that has been claimed by some researchers to be more proficient deposition technique to achieve that as it is simple and reproducible [16]. In view of this, we intend to use chemical bath deposition technique which is simpler, more cheaper and reproducible than spry pyrolitic method and some other methods that have been hitherto used to dope $\mathrm{ZnO}$ thin films with aluminium to deposit AZnO thin film and to analyze the influence of the variation of aluminium as a dopant on the optical properties of the thin film [17].

\section{Experimental Procedure}

$\mathrm{ZnO}$ thin films prepared by CBD method is based on the heating of alkaline bath of zinc asalt containing the substrates immersed in it. $0.1 \mathrm{M}$ of zinc sulphate was used as a source of zinc, to make the solution alkaline, aqueous ammonia solution was added with constant stirring. Firstly, the solution became milky-turbid due to the formation of zinc hydroxide $\mathrm{Zn}(\mathrm{OH})^{2-}$. Further addition of excess ammonia dissolved the turbidity and made the solution clear and transparent [18]. The $\mathrm{pH}$ value of the resultant solution was 11.0. The substrates were immersed in the bath at room temperature and the bath was heated at a temperature of 343K for 2hours, heterogeneous reaction occurred and the deposition of $\mathrm{ZnO}$ took place on the substrates. The $\mathrm{ZnO}$ coated substrates were removed from the bath washed with distilled water, dried in air and preserved in an air-tight container. These procedure leads to deposition on undoped $\mathrm{ZnO}$ on the glass substrate. To deposit Aluminium doped $\mathrm{ZnO}(\mathrm{AZnO})$ thin film, three different concentrations of $\mathrm{Al}$ dopants $\mathrm{ZnO}$ were used a follows; $0.1 \mathrm{M}, 0.2 \mathrm{M} \& 0.3 \mathrm{M}$ of $\mathrm{Al}$ to the starting material. The optical characteristic within the ultraviolet and near infra-red region of electromagnetic wave spectra was analysed using UV-VIS spectroscopy.

\section{Equation of Reaction}

$$
\begin{gathered}
\mathrm{ZnSO}_{4} \cdot 7 \mathrm{H}_{2} \mathrm{O} \text { Ç } \mathrm{Zn}^{2+}+\mathrm{SO}_{4}^{2-}+7 \mathrm{H}_{2} \mathrm{O} \\
\mathrm{C}_{6} \mathrm{H}_{12} \mathrm{~N}_{4}+6 \mathrm{H}_{2} \mathrm{O} \text { Ç } \quad 6 \mathrm{CH}_{2}+4 \mathrm{NH}_{3} \\
\mathrm{NH}_{3}+\mathrm{H}_{2} \mathrm{O} \text { Ç } \mathrm{NH}_{4}^{+}+\mathrm{OH}^{-} \\
2 \mathrm{OH}^{-}+\mathrm{Zn}^{2+} \mathrm{C} \\
\mathrm{ZnO}+\mathrm{H}_{2} \mathrm{O}
\end{gathered}
$$

$$
\begin{gathered}
\mathrm{Al}\left(\mathrm{NO}_{2}\right)_{3} .9 \mathrm{H}_{2} \mathrm{O} \text { Ç } \mathrm{Al}^{3+}+3 \mathrm{NO}_{3}^{-} \\
\mathrm{ZnO}+\mathrm{Al}^{3+} \rightarrow \mathrm{ZnO} \cdot \mathrm{Al}
\end{gathered}
$$

\section{Result and Discussion}

The results of the work are as presented in the Figure 1 and Figure 2 showing the spectral transmittance and reflectance while Figure 3 depicts absorbance, while that of Figures 4 and 5 represent the a plot of $(\alpha \mathrm{h} v)^{2}$ against photon energy from where the band gaps was deduced considering the extrapolation if the graph to intercept the energy axis at $(\alpha h v)^{2}$ equals zero.

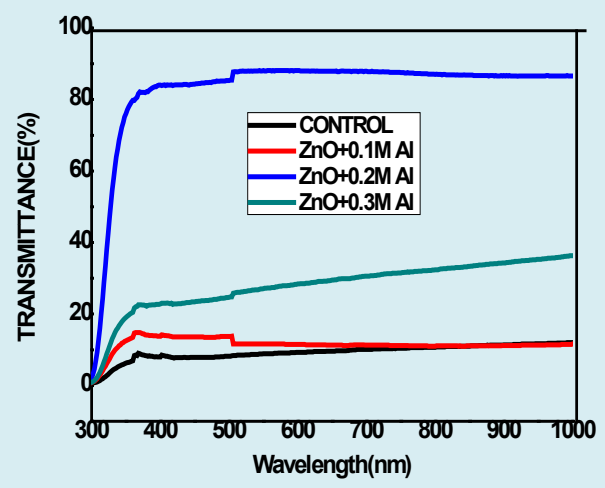

Figure 1: Transmittance Spectra of undoped $\mathrm{ZnO}$ and $\mathrm{AZnO}$ doped with different $\mathrm{Al}$ concentrations.

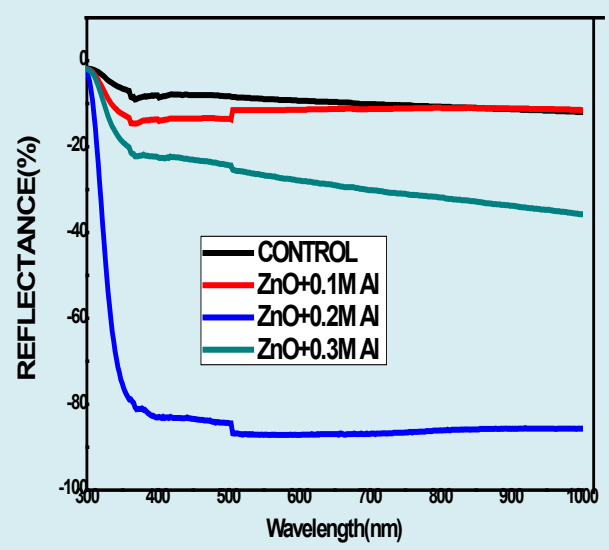

Figure 2: Reflectance against wavelength of undoped $\mathrm{ZnO}$ and $\mathrm{AZnO}$ with different $\mathrm{Al}$ concentrations. 


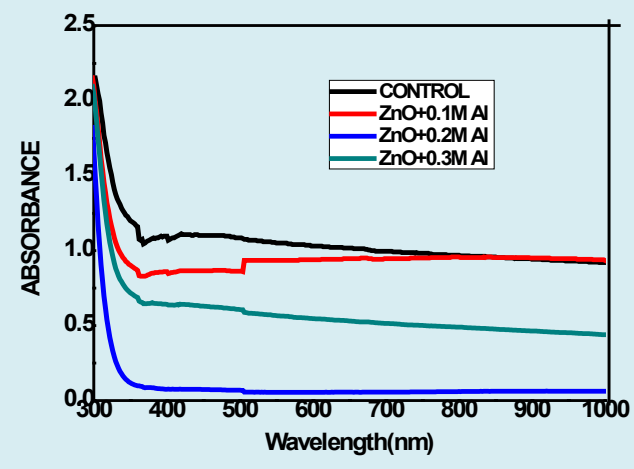

Figure 3: Absorbance against wavelength of undoped $\mathrm{ZnO}$ and $\mathrm{AZnO}$ different $\mathrm{Al}$ concentrations.
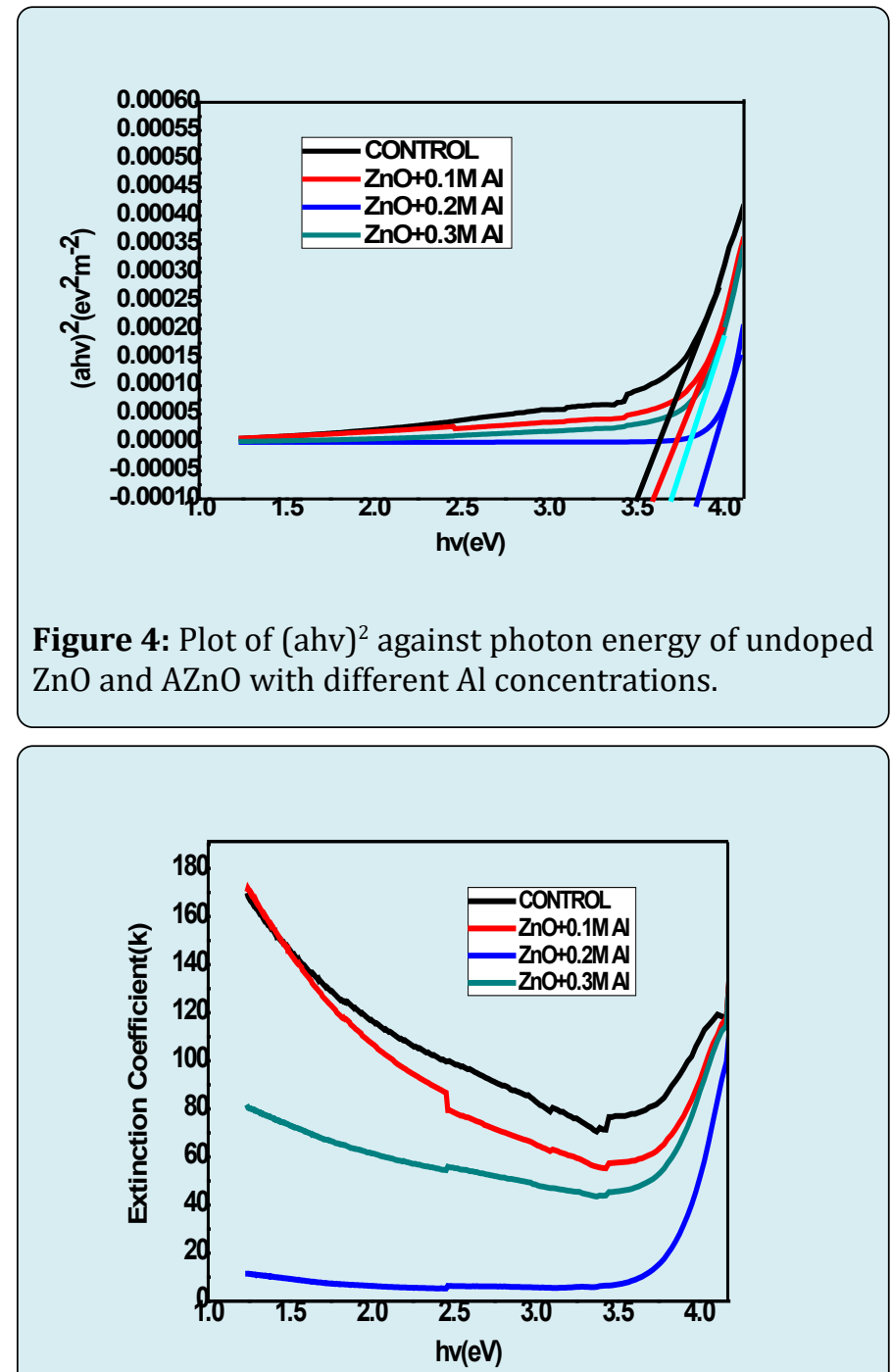

Figure 5: Extinction Coefficient verses photon energy of undoped $\mathrm{ZnO}$ and $\mathrm{AZO}$ with different $\mathrm{Al}$ concentrations.

\section{Transmittance}

Figure 1 shows the of transmittance spectra against wavelength, the films depicts high transmittance at visible region to near infra-red region and low transmittance at the ultra violet region. The transmittance increased with increase in aluminium concentration this is because addition of aluminium improves the crystal structure which results to reduced surface roughness. The value of transmittance for $\mathrm{ZnO}$ films is high $(20-90 \%)$ in the spectral region which matches maximum sensitivity for photonic vision. This suggests that the films could be employed as a transparent oxide in solar cells.

\section{Reflectance}

Figure 2 The Plot shows that for all $\mathrm{ZnO}$ thin films, the reflectance is high within the visible region and gradually decreased between 300 to $400 \mathrm{~nm}$. The highest value recorded is $>-2 \%$ while the lowest value recorded is $<-80 \%$. The films reflectance is seen to be decreasing with increase in doping concentration which suggest that this material is good for use as anti-reflectance or in anti-reflection coating.

\section{Absorbance}

Plots of absorbance verses wavelength is as shown in Figure 3. The plot indicates that all the films are absorbing within the visible region of the spectrum, and it also show that the absorbance is lowered with increase in aluminium concentration. The film exhibited high spectral absorbance at a wavelength $200 \mathrm{~nm}$ which falls exponentially to $400 \mathrm{~nm}$ and gradually decrease with increase in wavelength that appears to vary with increase in the increase of the aluminium dopant. This suggests that the doping has significant effect on the material and as such serves as good material for the building of poultry roofs and walls to warm the inside of the poultry house for chicken brooder [19].

\section{Band Gap}

Figure 4 shows the plot of $(a h v)^{2}$ vs $h v$ which reveals that the electronic energy band gap of $\mathrm{ZnO}$ is dependent on concentration of its constituent elements The optical band gap increased in accord with an increase in concentration of aluminium dopant and the value is within the range of (3.5-3.8eV). The observed band gaps are within the range of values reported by Mondal S [20].

\section{Extinction Coefficient}

It is observed from Figure 5 that extinction coefficient, decreased up to the region of the fundamental absorption that is the range of photon energies at which the energy band gap occurred and then increased afterward. However, 
the values of for undoped sample is higher compared to that of doped which means that aluminium dopant decreases the extinction coefficient of $\mathrm{ZnO}$. Also seen is a gradual increase in of values after band gap value towards the higher photon energy value and the positive value shows that the material is strongly absorbing which will be ascribed to the surface smoothness of the sample and uniformity of the solution.

\section{Conclusion}

Transparent $\mathrm{ZnO}$ thin films doped with Aluminium were prepared by Chemical bath Deposition techniques and the effect of Aluminium concentrations on the optical properties were studied. The absorbance plot reveals that all the deposited $\mathrm{ZnO}$ thin films are absorbing in the visible region of the spectrum at different maxima wavelength between $300 \mathrm{~nm}-450 \mathrm{~nm}$ and that increase in Al concentrations causes decrease in absorbance value of the film is a proof that $\mathrm{Al}$ dopant have profound effect on the optical properties of the films. High absorbance in the UV region also makes the films better material for the building of poultry roofs and walls to warm the inside of the poultry house and the high absorbance of the deposited $\mathrm{ZnO}$ thin films suggests that they can also be used in solar cell fabrication as an absorber. From the transmittance plots, the deposited $\mathrm{ZnO}$ films have relative high transmittance at the visible to infrared region and the transmittance increases with increase in Al concentrations. high transmittance in the visible region and wide energy band gap shown by these films, suggest that these films could be employed in solar cell architecture as window layer. The energy band gaps of these films fall within the range of $(3.5-3.9 \mathrm{eV})$. This increase in band gap as doping concentration increases shows that aluminium dopant enhances the band gap and the wide band gap exhibited by these films, suggest that these films are good materials for application in laser diode and photovoltaic applications. In general, the deposited film is a possible material that can be used for solar application.

\section{References}

1. He WW, Ye CH (2015) Flexible transparent conductive films on the basis of Ag nanowires: design and applications. A review J Mater Sci Techol 31(6):581-588.

2. Lin JJ, Li ZQ (2014) Electronic conduction properties of indium tin oxide: single-particle and many-body transport. J Phys Condens Matter 26: 343201.

3. Shan FK, Yu YS (2005) Band gap energy of pure and Aldoped $\mathrm{ZnO}$ thin films. Journal of the European Ceramic Society 24(6): 1869-1872.

4. Kim YS, Tai WP, Shu SJ (2005) Effect of preheating temperature on Structural and optical properties of $\mathrm{ZnO}$ thin films by sol-gel process. Thin Solid Films 491(1-2): 153-160.

5. Pogrebnjak AD, Jamil NY, Muhammed AKM (2011) Structural and optical properties of $\mathrm{ZnO}$ prepared by CVD before and after annealing, Metallofiz. Noveishie Tekhnol 33: 235-241

6. Alaeddin A, Rachidi I, Bahsoun F, Mohanna Y, Bazzi O, et al. (2009) Influence of Al Dopant on the Optical and Electrical properties of $\mathrm{ZnO}$ Thin Films Prepared by Spray pyrolysis. Journal of Applied Sciences 9(8): 15881592.

7. Leenheer A, Perkins J, van Hest M, Berry J, O'Hayre R, et al. (2008) General mobility and carrier concentration relationship in transparent amorphous indium zinc oxide films. Phy Rev B 77(11): 115215.

8. Bhosle V, Tiwari A, Narayan J (2006) Metallic conductivity and metal semiconductor transition in Gadoped ZnO. Appl Phys Lett 88: 032106.

9. Kim D, Yun I, Kim H (2010) Fabrication of rough Al doped $\mathrm{ZnO}$ films deposited by low pressure chemical vapor deposition for high efficiency thin film solar cells. Curr Appl Phys 10(3): 459-462.

10. Steinhauser J, Fay S, Oliveira N, Vallat-Sauvain E, Ballif C (2007) Transition between grain boundary and intragrain scattering transport mechanisms in borondoped zinc oxide thin films. Appl Phys Lett 90(14): 142107.

11. Jimenez-Gonzale AE, Soto-ureta JA, Suarez-para $R$ (1998) Optical and electrical characteristics of Aluminum dopes $\mathrm{ZnO}$ thin films prepared by Sol gel techniques. J Cryst Growth 192: 430-438.

12. Benhaoua B, Rahal A, Benramache S (2014) The structural, optical and electrical properties of nanocrystalline $\mathrm{ZnO}$ :Al thin films. Superlattice Microst 68: 38-47.

13. Bandyopadhyay S, Paul GK, Sen SK (2002) Study of optical properties of some sol-gel derived films of ZnO. Solar Energy Materials and Solar Cells 71: 103-113

14. Pogrebnjak AD, Jamil NY, Muhamed AM (2011) Electrical and optical properties of $\mathrm{ZnO}$ :Al films prepared by chemical vapour deposition (CVD)/Proceedings of 1st International conference "Nanomaterials: Applications \& properties" (NAP-2011). - Ukraine, Crimea, Alushta, pp: 226-232.

15. Pogrebnjak AD, Muhamed AKM (2011) Simulation Study of Effect on Thin Film GIGS Solar Cell Perfomence. 
J Nano-Electron Phys 3: 52-59.

16. Rozati SM, Akese SA (2007) Influence of substrate temperature on the structure of $\mathrm{ZnO}$ :Al thin films, Cryst. Res Technol 43: 273-275.

17. Krunks K, Bijakina O, Mikli V, Varema T, Mellikov E (1999) Zinc oxide thin films by spray pyrolysis method. Physica Scripta 1999(T79): 209.

18. Anglada E, Gonzalez HL (1998) U.S. Patent No. 5,805,520.
U.S. Patent and Trademark Office, Washington DC.

19. Ugwu EI (2018) The Effect of Annealing, Doping on the Properties and Functionality of Zinc Oxide Thin Film; Review. In Sol-Gel Method-Design and Synthesis of New Materials with Interesting Physical, Chemical and Biological Properties, Chapter 2, Intech Open.

20. Mondal S, Mitra P (2012) Preparation of cadmium-doped ZnO thin films by SILAR and their characterization. Bulletin of Materials Science 35(5): 751-757. 